\title{
Consent for genetic research in a general population: The NHANES experience
}

\author{
Geraldine M. McQuillan, PhD ${ }^{1}$, Kathryn S. Porter, $M D, M S^{1}$, Maria Agelli, MD, MS ${ }^{2}$, and Raynard Kington, $M D, P h D^{3}$
}

\begin{abstract}
Purpose: To determine the sociodemographic factors associated with consent for storage of DNA for future genetic research. Methods: Analysis of the characteristics of consenting individuals participating in the National Health and Nutrition Examination Survey, a nationally representative survey of the US household population. Results: In 1999, 84\% (95\% confidence interval 82.4-85.6) of eligible participants consented to have their blood samples included in a national repository for genetic research. In 2000, 85.3\% (95\% confidence interval 84.0-86.6) consented. Females and black participants in both years were least likely to consent (1999, $82.2 \%$ and $73.2 \%$; $2000,83.6 \%$ and $81.3 \%$, respectively). An assessment by logistic regression demonstrated that in both years only non-Hispanic black race/ethnicity was a significant independent predictor for not consenting to future genetic research. Conclusion: Although non-Hispanic black individuals have overall response rates similar to those of the other racial/ethnic groups, they are less likely to agree to have a blood sample saved for future genetic research. In balance, however, these findings demonstrate wide acceptance among survey participants for allowing storage of specimens for future genetic research across many demographic variables. Genet Med 2003:5(1):35-42.
\end{abstract}

Key Words: informed consent, genetic research, survey, representative sample, household population

With the recent advances in the understanding of the human genome, the scientific community has begun to recognize the importance of stored biologic samples and of population databases with genetic, phenotypic, and sociodemographic data. ${ }^{1-4}$ Such databases may be of value both for estimating the distribution of various alleles in the general population and in specific subpopulations as well as for helping to understand the causal pathways for common diseases that result from complex interactions between genetic and environmental factors. The addition of the collection and storage of blood samples for genetic research was proposed to be included in the current National Health and Nutrition Examination Survey (NHANES) primarily because the ongoing survey already includes extensive sociodemographic and clinical data. Furthermore, NHANES is the only national survey that collects biologic specimens from a representative sample of the US population.

Although there has been research on the public's attitudes toward the use of biologic samples for genetic research, ${ }^{5}$ there is little empirical evidence on the willingness of research participants from a general population to consent to have their

\footnotetext{
From the ${ }^{1}$ Division of Health Examination Statistics, National Center for Health Statistics, Centers for Disease Control and Prevention, Hyattsville, Maryland; ${ }^{2}$ National Cancer Institute, National Institutes of Health, Bethesda, Maryland; and ${ }^{3}$ Office of Behavioral and Social Sciences Research, National Institutes of Health, Bethesda, Maryland.

Geraldine M. McQuillan, PhD, National Center for Health Statistics, 6525 Belcrest Road, Room 1000, Hyattsville, MD 20782.

Received: August 21, 2002.

Accepted: November 6, 2002.
}

DOI: 10.1097/01.GIM.0000048372.64172.15 genetic material included in repositories for research purposes. Because NHANES used a unique, separate consent procedure to document consent by participants for the storage and future genetic testing of blood samples, these data present a unique opportunity to assess the predictors of consent in a general population to have genetic samples included in a research repository.

NHANES is a cross-sectional national survey that is representative of the US civilian noninstitutionalized population conducted by the National Center for Health Statistics (NCHS), Centers for Disease Control and Prevention (CDC). Although the survey has been conducted periodically in the past, the current survey will be fielded continuously.

In this study, we analyze data from the 1999 and 2000 NHANES to assess the sociodemographic predictors of the willingness to participate in genetic research in a diverse, general study population.

\section{METHODS}

\section{Survey design}

The NHANES provides national statistics on the health and nutritional status of the civilian noninstitutionalized population of the United States through household interviews and a standardized physical examination in special mobile examination centers. Beginning in 1999, NHANES became a continuous survey with each survey year based on a nationally representative sample of the US civilian noninstitutionalized population. The procedures followed to select the sample and conduct the interview and examination were similar to those used in previous years. ${ }^{6}$ The goals of NHANES are to monitor 
the nation's health by estimating the number and percentage of persons in the US population and in designated subgroups with selected diseases and risk factors; monitoring trends in the prevalence, awareness, treatment, and control of selected diseases; monitoring trends in risk behaviors and environmental exposures; analyzing risk factors for selected diseases; studying the relationship between diet, nutrition, and health; exploring emerging public health issues and new technologies; and establishing a national probability sample of genetic material for future genetic research.

Data collection for NHANES occurs at three levels: a brief household screener interview, an in-depth household survey interview, and a medical examination. Consent for the examination and the collection of the DNA specimen was obtained after the individual was selected for participation in the study and the household interview was completed. Only participants aged 20 or more years were eligible for this collection. Consent for the collection of the DNA specimen was obtained separately from the consent for the examination. The NHANES survey and consent documents were approved by the CDC Institutional Review Board.

The analyses are presented in this report separately for 1999 and 2000 because small changes were made in the consent documents after the 1999 data collection (Appendices 1 and 2). In 1999, the consent form was titled "Consent for Specimen Storage and Future Research." Although only participants aged 20 or more years were asked to agree to future genetic research, younger participants and their parents were asked whether they would agree to the storage of blood or urine for other research projects (i.e., assessing exposures to environmental chemicals or infectious diseases). For the 1999 data collection, there were separate documents for consent, assent (for children older than age 7), and parental permission. Based on feedback from field staff during 1999, in 2000 these multiple consent documents were combined into one document and the title was changed to "Consent/Assent and Parental Permission for Specimen Storage and Continuing Studies." This wording change, made with the approval of the NHANES Institutional Review Board, was designed to address concerns raised by the NHANES interviewers that the word "research" was not well understood by the public. NHANES participants are informed that all the health data collected will be kept strictly private and that unless they agree the staff are not allowed to discuss their participation in the survey under penalty of federal law: Sections 308 (d) of the Public Health Service Act (42 USC 242 m) and the Privacy Act of 1974 (5USC 552C) (http://www. cdc.gov/nchs/data/nhanes/99bkpant.pdf). The DNA samples and all stored specimens and data from the survey cannot be identified by nonstaff researchers or anyone using the data files. Data are recategorized or top-coded if there is any potential for identification of participants.

The purpose of the stored specimens was to provide a resource for new scientific tests including genetic laboratory tests that were not available when the participant was examined. Therefore, the participant was informed that no specific studies were currently planned and that researchers using their samples would not be contacting them for any additional information. They were also told that NCHS would not contact them with specific results, but would provide information on the studies being conducted in a newsletter and that proposals for use of their specimens would be reviewed for scientific merit and by an institutional review board to ensure that the proposed research was ethical. Finally, they were also told they could remove their specimens at any time and were given a toll-free number to get more information about a particular study.

During 1999, 2721 adults aged 20 years and older were selected to participate. In 2000, 3680 participants aged 20 years and older were selected.

Information on race and ethnicity was collected in two stages, as part of the screener interview and as a part of the in-home household interview. The race/ethnicity variables in Table 1 were based on information obtained through a screener, often provided by a single household member who reported basic demographic data on persons in the household for the purpose of sample selection. This screening was based on two questions asked at the door for Mexican American or Hispanic ethnicity, then the selection of a race category. The race/ethnicity data from the screener interview differ slightly from the final data obtained from multiple questions asked of the participant in the interview (13 recoded to non-Hispanic white in 1999; eight recoded to non-Hispanic white in 2000).

Race/ethnicity was categorized as non-Hispanic white, nonHispanic black, and Mexican American. Individuals who did not self-select into these categories were classified as "other." The poverty index ratio was calculated by dividing total family income by the poverty threshold index adjusted for family size at year of interview. All interviews were translated into either English or Spanish. If another language was spoken by the participant, a family member or local interpreter translated the interview into English.

Because the 1999 survey had lower response rates than usually obtained in NHANES, an extensive public relations campaign was begun late in 1999 to explain better the survey and to increase public acceptance. NHANES improved working relationships with local health departments and local public affairs authorities, enhanced outreach to the communities through church and community organizations, improved and simplified consent documents, and developed outreach materials that addressed specific concerns of segments of the population. These materials included a brochure designed to address the legacy of the Tuskegee syphilis study which outlined reforms in human subject protection, fact sheets for Mexican Americans and African Americans, and a brochure for pregnant women. These materials were used if a potential participant raised these issues. Interviewers reported that these materials were very useful answering concerns and in obtaining respondent cooperation. Although response rates to the survey increased $8 \%$ between 1999 and 2000, the impact of specific efforts could not be assessed.

The category of future nongenetic research on the consent documents was specified so participants could agree to having their blood kept for other laboratory tests if they were not 
Table 1

Overall interview response rates for NHANES 1999-2000 participants aged 20 or more years by demographic categories

\begin{tabular}{|c|c|c|c|c|c|c|}
\hline \multirow[b]{2}{*}{$\begin{array}{l}\text { Demographic } \\
\text { characteristic }\end{array}$} & \multicolumn{3}{|c|}{1999} & \multicolumn{3}{|c|}{2000} \\
\hline & $\begin{array}{c}\text { No. } \\
\text { eligible }\end{array}$ & $\begin{array}{c}\text { No. } \\
\text { interviewed }\end{array}$ & $\%(95 \% \mathrm{CI})^{a}$ & $\begin{array}{l}\text { No. } \\
\text { eligible }\end{array}$ & $\begin{array}{c}\text { No. } \\
\text { interviewed }\end{array}$ & $\%(95 \% \mathrm{CI})^{a}$ \\
\hline Total & 2721 & 1947 & $71.6(69.9-73.3)$ & 3680 & 2933 & $79.7(78.3-81.0)$ \\
\hline \multicolumn{7}{|l|}{ Race/ethnicity ${ }^{b}$} \\
\hline $\begin{array}{l}\text { Non-Hispanic } \\
\text { white }\end{array}$ & 1330 & 882 & $66.3(63.8-68.9)$ & 1696 & 1330 & $78.4(76.5-80.4)$ \\
\hline $\begin{array}{l}\text { Non-Hispanic } \\
\text { black }\end{array}$ & 427 & 306 & $71.7(67.4-75.9)$ & 811 & 627 & $77.3(74.4-80.2)$ \\
\hline Mexican American & 790 & 630 & $79.8(76.9-82.6)$ & 758 & 658 & $86.8(84.4-89.2)$ \\
\hline Other & 174 & 129 & $74.1(67.6-80.6)$ & 415 & 318 & $76.6(72.6-80.7)$ \\
\hline \multicolumn{7}{|l|}{ Gender } \\
\hline Male & 1302 & 920 & $70.7(68.2-73.1)$ & 1721 & 1349 & $78.4(76.4-80.3)$ \\
\hline Female & 1419 & 1027 & $72.4(70.1-74.7)$ & 1959 & 1584 & $80.9(79.1-82.6)$ \\
\hline \multicolumn{7}{|l|}{ Age } \\
\hline $20-29$ & 468 & 361 & $77.1(73.3-80.9)$ & 585 & 510 & $87.2(84.5-89.9)$ \\
\hline $30-39$ & 497 & 345 & $69.4(65.4-73.5)$ & 577 & 479 & $83.0(80.0-86.1)$ \\
\hline $40-49$ & 425 & 310 & $72.9(68.7-77.2)$ & 571 & 455 & $79.7(76.4-83.0)$ \\
\hline $50-59$ & 308 & 223 & $72.4(67.4-77.4)$ & 487 & 363 & $74.5(70.7-78.4)$ \\
\hline $60+$ & 1023 & 708 & $69.2(66.4-72.0)$ & 1460 & 1126 & $77.1(75.0-79.3)$ \\
\hline
\end{tabular}

${ }^{a} 95 \%$ confidence interval.

${ }^{b}$ Race/ethnicity is based on the screener collected for sampling purposes and therefore differs slightly from categories in Table 2 (see description in "Methods" section).

comfortable with genetic research. Only 14 individuals in 1999 and 32 in 2000 did not consent to genetic research while still agreeing to other types of future health research. In 1999, 96\% of interviewed individuals agreed to be examined and $87 \%$ of examined individuals aged 20 or more years agreed to phlebotomy. In 2000, $98 \%$ of those interviewed agreed to be examined and $88 \%$ had phlebotomy. There were no significant racial/ ethnic differences in the examination or phlebotomy rates in both years.

\section{Statistical analysis}

These analyses are based on data used to monitor the survey operations. Rates are therefore not weighted to produce national estimates. Consent rates, $95 \%$ confidence intervals, and logistic regression analysis were computed with SAS version 8.2 (SAS Institute, Inc., Cary, NC). Comparisons were performed with the $\chi^{2}$ test. All $P$ values quoted are two-tailed. The "other" racial group was deleted from the logistic regression because of the small sample size and the diverse composition of the group. The language of interview could also not be modeled, as it was not evenly distributed among the three racial/ ethnic groups.

\section{RESULTS}

Table 1 presents the overall response rates to the household interview in 1999 and 2000 for individuals aged 20 or more years. Although survey response rates exceeded 70\% in 1999 , response was significantly higher in 2000. This increase was seen in every race, sex, and age group. The largest increases in response were for non-Hispanic whites and participants under the age of 40 years.

Of the 2721 individuals aged 20 or more years selected for the survey in 1999, 1947 (71.6\%) completed the interview and were eligible to sign the consent for storage of their DNA for future genetic studies. Of these, $1635(84.0 \%)$ agreed to the collection of the DNA specimen (Table 2). In 2000, of the 3680 individuals in this age group selected, 2933 (79.7\%) completed the interview, and of these, 2501 (85.3\%) agreed to the DNA specimen collection.

Table 2 presents the characteristics of those eligible to sign the genetic consent document by demographic categories for 1999 and 2000. The lowest consent rates were for non-Hispanic blacks in both years, although the response was significantly higher for blacks in 2000 compared with 1999. In both years females were significantly less likely to consent $(P<0.05)$ than males. This gender difference was seen in both years for all racial/ethnic groups except "others" but was only significant $(P<0.05)$ for non-Hispanic whites (data not shown). In both years the youngest and oldest age groups had the lowest genetic consent rates. Consent rates were more variable by demographic categories in 1999 compared with 2000, but indicators of economic sta- 
Table 2

Consent to genetic research for NHANES 1999-2000 interviewed participants aged 20 or more years by demographic categories

\begin{tabular}{|c|c|c|c|c|c|c|}
\hline \multirow[b]{2}{*}{$\begin{array}{l}\text { Demographic } \\
\text { characteristic }\end{array}$} & \multicolumn{3}{|c|}{1999} & \multicolumn{3}{|c|}{2000} \\
\hline & $\begin{array}{c}\text { No. } \\
\text { interviewed }\end{array}$ & $\begin{array}{c}\text { No. } \\
\text { consented }\end{array}$ & $\%(95 \% \mathrm{CI})^{a}$ & $\begin{array}{c}\text { No. } \\
\text { interviewed }\end{array}$ & $\begin{array}{c}\text { No. } \\
\text { consented }\end{array}$ & $\%(95 \% \mathrm{CI})^{a}$ \\
\hline Total & 1947 & 1635 & $84.0(82.4-85.6)$ & 2933 & 2501 & $85.3(84.0-86.6)$ \\
\hline \multicolumn{7}{|l|}{ Race/ethnicity ${ }^{b}$} \\
\hline Non-Hispanic white & 895 & 766 & $85.6(83.3-87.9)$ & 1338 & 1179 & $88.1(86.4-89.9)$ \\
\hline Non-Hispanic black & 302 & 221 & $73.2(68.2-78.3)$ & 621 & 505 & $81.3(78.3-84.4)$ \\
\hline Mexican American & 625 & 538 & $86.1(83.4-88.8)$ & 658 & 548 & $83.3(80.4-86.1)$ \\
\hline Other & 125 & 110 & $88.0(82.3-93.7)$ & 316 & 269 & $85.1(81.2-89.1)$ \\
\hline \multicolumn{7}{|l|}{ Sex } \\
\hline Male & 920 & 791 & $86.0(61.5-66.8)$ & 1349 & 1177 & $87.3(85.5-89.0)$ \\
\hline Female & 1027 & 844 & $82.2(79.8-84.5)$ & 1584 & 1324 & $83.6(81.8-85.4)$ \\
\hline \multicolumn{7}{|l|}{ Age } \\
\hline $20-29$ & 361 & 299 & $82.8(78.9-86.7)$ & 510 & 436 & $85.5(82.4-88.6)$ \\
\hline $30-39$ & 345 & 286 & $82.9(78.9-86.9)$ & 479 & 422 & $88.1(85.2-91.0)$ \\
\hline $40-49$ & 310 & 264 & $85.2(81.2-89.1)$ & 455 & 400 & $87.9(84.9-90.9)$ \\
\hline $50-59$ & 223 & 194 & $87.0(82.6-91.4)$ & 363 & 314 & $86.5(83.0-90.0)$ \\
\hline $60+$ & 708 & 592 & $83.6(80.9-86.3)$ & 1126 & 929 & $82.5(80.3-84.7)$ \\
\hline \multicolumn{7}{|l|}{ Years of education ${ }^{c}$} \\
\hline Less than HS & 736 & 611 & $83.0(80.0-85.7)$ & 1159 & 985 & $85.0(82.9-87.0)$ \\
\hline HS diploma & 375 & 307 & $81.9(78.0-85.8)$ & 722 & 632 & $87.5(85.1-90.0)$ \\
\hline Some college & 826 & 707 & $85.6(83.2-87.9)$ & 1037 & 881 & $85.0(82.8-87.1)$ \\
\hline \multicolumn{7}{|l|}{ Language of interview ${ }^{d}$} \\
\hline English & 1706 & 1440 & $84.4(82.7-86.1)$ & 2464 & 2098 & $85.2(83.7-86.6)$ \\
\hline Spanish & 236 & 191 & $80.9(75.2-85.7)$ & 449 & 387 & $86.2(83.0-89.4)$ \\
\hline \multicolumn{7}{|l|}{ Poverty index ${ }^{e}$} \\
\hline$<1$ & 272 & 226 & $83.1(78.6-87.5)$ & 587 & 509 & $86.7(84.0-89.5)$ \\
\hline$\geq 1$ & 1221 & 1066 & $87.3(85.4-89.2)$ & 1832 & 1629 & $88.9(87.5-90.4)$ \\
\hline
\end{tabular}

${ }^{a} 95 \%$ confidence interval.

${ }^{b}$ Confirmed race/ethnicity based on race/ethnicity questions obtained in the household interview from the participant.

${ }^{c} 10$ individuals with missing education in 1999, 15 in 2000. HS, high school.

${ }^{d} 5$ interviews in other language in 1999, 20 in 2000.

${ }^{e}$ Individuals with missing poverty index had lower response rates for genetic consent $(1999 n=454,75.6 \% ; 2000 n=514,70.6 \%)$.

tus, education, and poverty level were not significantly associated with differences in either year.

A logistic regression was performed to determine which factors independently contributed to a willingness to consent in the two study years (Table 3). Only non-Hispanic black race/ ethnicity remained associated with an unwillingness to consent to genetic research in both years. In 2000 Mexican Americans were also less likely to consent.

\section{DISCUSSION}

NHANES is the only national survey that collects biologic samples on a representative sample of the US population. The debate on the appropriate consent for genetic research is not a new one for the program. Blood lymphocytes were collected in the previous survey (NHANES III, 1988-1994) in anticipation of advances in genetic research. Although the consent document used in that survey informed participants that some of the blood collected would be stored for future testing, genetic research was not specifically mentioned. This collection and the ethical issues of using the stored samples resulted in a workshop and consensus statement addressing the need for specific consent for genetic studies. ${ }^{7}$ This context was the basis for the development of the informed consent documents for future research from specimens collected in the current survey. The assessment of acceptance of this collection is important 
Table 3

Relative odds for lack of consent to genetic research from logistic regression in adult participants aged 20 years and older, NHANES 1999 and 2000

\begin{tabular}{lcc}
\hline \multirow{2}{*}{$\begin{array}{l}\text { Demographic } \\
\text { characteristic }\end{array}$} & \multicolumn{2}{c}{ Odds ratio $(95 \% \text { CI })^{a}$} \\
\cline { 2 - 3 } Race/ethnicity $^{b}$ & & \\
Non-Hispanic black & $2.3(1.5-3.5)$ & $1.9(1.4-2.6)$ \\
Mexican American & $0.7(0.4-1.1)$ & $1.5(1.1-2.2)$ \\
Non-Hispanic white & Reference group & Reference group \\
Sex & & \\
Female & $1.4(1.0-1.9)$ & $1.3(1.0-1.7)$ \\
Male & Reference group & Reference group \\
Age & & \\
$20-29$ & $1.0(0.6-1.6)$ & $0.8(0.6-1.2)$ \\
$30-39$ & $0.8(0.5-1.3)$ & $0.7(0.4-1.0)$ \\
$40-49$ & $0.9(0.6-1.4)$ & $0.6(0.4-1.0)$ \\
$50-59$ & $0.7(0.4-1.3)$ & $0.7(0.5-1.1)$ \\
$60+$ & Reference group & Reference group
\end{tabular}

Years of education

$\begin{array}{lcc}\text { Some high school } & 1.3(0.8-2.0) & 0.7(0.5-1.0) \\ \text { High school graduate } & 1.3(0.9-2.0) & 0.7(0.5-0.9) \\ \text { Some college } & \text { Reference group } & \text { Reference group }\end{array}$

Poverty index

$<1$

$1.3(0.8-1.9)$

$1.3(1.0-1.8)$

$\geq 1$

Reference group

Reference group

${ }^{a} 95 \%$ confidence interval.

${ }^{b}$ Confirmed race/ethnicity based on race/ethnicity questions obtained in the household interview from the participant.

because of the value of a nationally representative repository of genetic material and ability to generalize the knowledge gained from survey participants.

There has been speculation about the willingness of the general population to agree to participate in genetic research, ${ }^{5}$ although most studies addressing this issue have looked at participation in clinical settings and are based on genetic testing of members of high-risk families or on the storage of samples related to a specific disorder. ${ }^{2,7-12}$ A recent study in Sweden demonstrated high response rates (93\%) when a randomly selected sample were recontacted and asked whether blood previously collected could be used for academic genetic research. ${ }^{13}$ One of the challenges for NHANES was to develop a "Future Genetic Research" consent document that provided sufficient information for individuals to make an informed decision on the future use of their blood specimen for the broad category of health research. The survey is a general health study that covers a variety of topics; therefore, we did not want to restrict this national resource by limiting the future research to topic areas that might be outdated even before the resource could be used. ${ }^{14}$
Consent for the collection of a DNA specimen among those who agreed to the interview increased in all demographic groups between 1999 and 2000, possibly related to greater outreach activities as described in the "Methods" section. Despite these increases, there continued to be less acceptance of genetic research by females in every racial/ethnic group and non-Hispanic blacks in general. In both years, the NHANES program separated the consent for future nongenetic research from consent for genetic research to allow participants who were not comfortable with the concept of genetic research to have their biologic specimens to be kept for other research projects. This option was generally ignored by participants. They agreed to the storage of specimens and future research including genetic research as one concept with about $1.0 \%$ in both years checking the box for future research but not the box for genetic research.

Presenting the consent document and the fact sheet on genetic research to NHANES participants differs from recruitment and consent issues in other genetic research studies, and therefore these results might not be directly relevant to more targeted study populations. Participants in NHANES are not selected on the basis of any known disease or condition, but are representative of the US population as defined by age, race, and sex. The broad-based goals of the survey do not provide a motivation based on personal or familial interest in a disease. As many as 11 examination components, 40 separate questionnaire sections, and more than 200 laboratory tests are performed on participants depending on their age. Topic areas cover diverse areas of health research such as cardiovascular disease or sexually transmitted diseases.

Recent advances in molecular genetics and human genome research have provided new scientific tools but have also raised issues concerning the ethics of such research. ${ }^{15,16}$ In addition, DNA sampling and storage from populations has also been criticized, ${ }^{17}$ although this concept also has its supporters who believe that such collections are necessary to determine allele frequencies in populations to better understand disease and to develop potential interventions.,3 Finally, concerns about inclusion of all Americans in research, including minorities, has also received attention, especially with the US government efforts to include all racial/ethnic groups in human research. ${ }^{18}$

The results of this study suggest that there is broad-based general acceptance across the demographic groups for participation in genetic research such as that proposed for the NHANES genetic repository. There was some variation in acceptance in subgroups of participants, with lower response among blacks and females. The participation of African Americans in medical research has been widely discussed in the medical literature because of the historical relative absence of racial/ethnic minorities in medical research and the recent government encouragement for their inclusion in all human subject research. ${ }^{8,9,18,19}$ The studies that have explored the concerns of African Americans about participating in clinical trials and familial cancer research have concluded that trust and community involvement are essential for adequate participation. ${ }^{8-10}$ Our results demonstrate that NHANES has overcome 
the barriers of African American participation in the survey, but a higher percentage than the other racial/ethnic groups opted out of the storage of blood for genetic research. Despite this disparity, combining data from 1999 and 2000, almost $80 \%$ of African Americans agreed to have their genetic samples included in a research repository. The general acceptance of the collection of a blood sample for genetic research encourages us that the program can continue to gain the trust necessary to reduce any disparities in genetic consent rates.

The lower percentage of females providing consent was surprising because studies on genetic testing in families with hereditary diseases have generally shown equal or more acceptance by women. ${ }^{11,12}$ Further research needs to be conducted to determine why this discrepancy exists.

There is increasing recognition of the need for populationbased data to understand the public health implications of genetic discoveries by determining the genetic variations across differing populations and ethnic groups. ${ }^{3,5,20}$ The availability of other biologic and environmental measures collected in NHANES increases the benefit of this resource. The challenge is to provide sufficient information so that participants can make an informed decision on their willingness to participate in the survey and to allow their blood to be stored for future genetic studies. Data from NHANES 1999-2000 provide empirical evidence that people will agree to genetic research even without the incentive of determining their own susceptibility for disease. The relative success of NHANES and the increase in consent rates between 1999 and 2000 demonstrate that with appropriate operations and outreach efforts, populationbased genetic studies can achieve high consent rates in a general population.

The lack of differences with regard to participation in the interview, examination, and phlebotomy but the presence of a racial/ethnic difference in the consent for future studies also suggests that researchers cannot assume consent for future genetic research among individuals participating in research projects. Specific consent must be obtained if an individual's autonomy is to be respected in all aspects of the research, both current and future.

\section{Acknowledgment}

US government funds were used to support the operation of the survey and these analyses.

\section{References}

1. National Bioethics Advisory Commission. Research involving human biologic materials: ethical issues and policy guidance, Vol 1: Report and recommendations of the National Bioethics Advisory Commission. Rockville, MD: National Bioethics Advisory Commission, 1999.

2. Knoppers BM, Laberge CM. Research and stored tissues: persons as sources, samples as persons? JAMA 1995;274:1806-1807.

3. Khoury M. From genes to public health: the application of genetic technology in disease prevention. Am J Public Health 1996;86:1717-1722.

4. Willett WC. Balancing life-style and genomics research for disease prevention. Science 2002;296:695-698.

5. Wang SS, Fridinger F, Sheedy KM, Khoury MJ. Public attitudes regarding the donation and storage of blood specimens for genetic research. Community Genet 2001; $4: 18-26$.

6. National Center for Health Statistics. Plan and operation of the third National Health and Nutrition Examination Survey, 1988-94. Vital Health Stat 1. 1994, No. 32.

7. Clayton EW, Steinberg KK, Khoury MJ, Thomson E, Andrews L, Kahn MJ et al. Informed consent for genetic research on stored tissue samples. JAMA 1995;274: 1786-1792.

8. Corbie-Smith G, Thomas SB, Williams MV, Moody-Ayers S. Attitudes and beliefs of African Americans toward participation in medical research. J Gen Intern Med 1999; 14:537-546.

9. Green BL, Partridge EE, Fouad MN, Kohler C, Crayton EF, Alexander L. AfricanAmerican attitudes regarding cancer clinical trials and research studies: results from focus group methodology. Ethn Dis 2000;10:76-86.

10. Kreiger N, Ashbury F Cotterchio M, Macey J. A qualitative study of subject recruitment for familial cancer research. Ann Epidemiol 2001;11:219-224.

11. Lerman C, Narod S, Schulman K, Hughes C, Gomez-Caminero A, Bonney G et al. $B R C A 1$ testing in families with hereditary breast-ovarian cancer: a prospective study of patient decision making and outcomes. JAMA 1996;275:1885-1892.

12. Lerman C, Hughes C, Trock BJ, Myers RE, Main D, Bonney A et al. Genetic testing in families with hereditary nonpolyposis colon cancer. JAMA 1999;17:1618-1622.

13. Stegmayr B, Asplund K. Informed consent for genetic research on blood stored for more than a decade: a population based study. BMJ 2002;325:634-635.

14. Lyttle J. Is informed consent possible in the rapidly evolving world of DNA sampling? CMAJ 1997;156:257-258.

15. Annas GJ. Rules for research on human genetic variation: lessons from Iceland. N Engl J Med 2000;342:1830-1833.

16. Schulte PA, Lomax GP, Ward EM, Colligan MJ. Ethical issues in the use of genetic markers in occupational epidemiologic research. J Occup Environ Med 1999;41:639_ 646.

17. Baird PA. Identifying people's genes: ethical aspects of DNA sampling in populations. Perspect Biol Med 1995;38:159-166.

18. US Department of Health and Human Services, Public Health Service, National Institutes of Health. Inclusion of women and minorities in study populations: instructions and information. Washington, DC: US Government Printing Office, 1990.

19. Shavers-Hornaday VL, Lynch CF, Burmeister LF, Torner JC. Why are African Americans under-represented in medical research studies? Impediments to participation. Ethn Health 1997;2:31-45.

20. Beskow LM, Burke W, Merz JF, Barr PA, Terry S, Penchaszadeh VB et al. Informed consent for population-based research involving genetics. JAMA 2001;286:23152321. 


\section{APPENDIX 1: 1999 CONSENT FORM}

\section{National Health and Nutrition E xamination Survey (NHANE S) Consent for Specimen Storage and Future Res earch (participants ages 18 years or over)}

\section{$Q$ Why will a sample of my blood and urine be kept for future research?}

$A$ We would like to store some of the urine, blood, and saliva you give us during your exam for future research studies. These specimens will be frozen in a specimen bank and will be used for as long as they last.

\section{$Q \quad$ What studies will be done with my samples?}

$\boldsymbol{A}$ At this time, no specific studies are planned besides the tests included in your NHANES exam. As scientists learn more about health and diseases, other studies will be conducted that may include your samples. Researchers conducting these studies will not contact you for any additional information.

We will keep strictly private all health data and samples that we collect in NHANES. Our staff is not allowed to discuss that you are part of this survey under penalty of Federal laws: Section 308(d) of the Public Health Service Act (42 USC $242 \mathrm{~m}$ ) and the Privacy Act of 1974 (5 USC 552A).

\section{$Q$ Who can use my stored samples for future research?}

$\boldsymbol{A}$ Researchers from Federal agencies, univ ersities, and other scientific centers can submit proposals to use your stored specimens. These proposals will be reviewed for scientific merit and by a board that determines if the research proposed is ethical. The NHANES program will always know which samples belong to you, but we will not give other researchers any information that could identify you.

\section{$Q \quad$ Will I receive results f rom any future research tests?}

$\boldsymbol{A}$ Most studies will simply add to our knowledge of health and disease. Therefore, we do not plan to contact you with individual results from these studies. Periodically we will send a newsletter telling all NHANES participants abo ut the research studies being conducted. To get more general information about a particular study, you can call our toll-free number shown below.

$Q \quad$ What genetic research $w$ ill be done and what part will my DNA sample play? (DNA samples will be collected only on those ages 20 or over.)

$\boldsymbol{A}$ Genetic studies look at the DNA found in cells. We will store part of the blood and saliva sample that we collect in the exam center for future genetic research. We will keep this material for an unlimited time. Studies of human genes are helping us learn about many diseases and health conditions. The information from people who are part of NHANES could help that effort.

If you do not wish to have your samples used for future genetic research, you will have a chance to say so when you sign this consent form.

\section{$Q \quad$ How can I remove my blood, urine or saliva samples} from the specimen bank?

$A$ In the future, if you want your samples removed from the specimen bank, call the toll-free number below.

The results of research on your stored specimens may help find new ways to prevent, treat, and cure many diseases. Please read the sentences below and think about your choice. Circle the answer that is right for you.

1. I agree that my blood, urine, and saliva may be kept for future research to help understand health and disease.

$$
\text { Yes No }
$$

2. (Only answer if you are 20 years old or older.) I agree that my blood and saliva may be kept for future research using my genes to help understand the genetic link to medical conditions (for example, causes of diabetes, heart disease, cancer or Alzheimer's disease).

Yes No

I understand that my individual results from research studies will not be made available to me. I can contact the NHANES staff at 1-800 452-6115 to have my sample withdrawn from future research at any time.

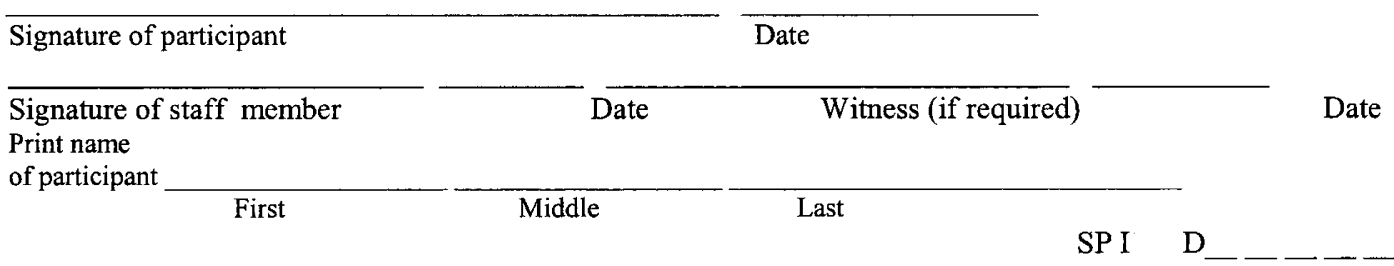


APPENDIX 2: 2000 CONSENT FORM

\author{
National Health and NUTRition EXamination SURVEy (NHANES)

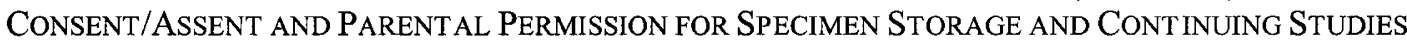

\author{
Print name of participant

First Middle Last \\ $Q$ Why will a sample of blood and urine be kept for future health \\ studies? \\ $Q \quad$ Will I receive results from any future testing of $\mathrm{my}$
specimens?
}

$\boldsymbol{A}$ We would like to store some of the urine, blood, and saliva from persons who are examined in NHANES for future health studies. These samples will be frozen and kept in a specimen bank for as long as they last.

$Q \quad$ What studies will be done with the samples?

$A$ At this time, no specific studies are planned besides the tests included in the NHANES exam. As scientists learn more about health and diseases, other studies will be conducted that may include stored samples. People conducting these studies will not contact NHANES participants for any additional information.

We will keep strictly private all health data and samples that we collect in NHANES. Our staff is not allowed to discuss that any person is part of this survey under penalty of Federal laws: Section 308(d) of the Public Health Service Act (42 USC 242m) and the Privacy Act of 1974 (5 USC 552A).

\title{
$Q$ Who can use the stored samples for further study?
}

$\boldsymbol{A}$ Researchers from Federal agencies, universities, and other scientific centers can submit proposals to use the stored specimens. These proposals will be reviewed for scientific merit and by a board that determines if the study proposed is ethical. The NHANES program will always know which samples belong to you or your child, but we will not give other researchers any information that could identify you or your child.

$A$ Most studies will simply add to our knowledge of health and disease. Therefore, we do not plan to contact you or your family with individual results from these studies. Periodically we will send a newsletter telling all NHANES participants about the studies being conducted. To get more general information about a particular study, you can call our toll-free number, 1-800 452-6115.

$Q \quad$ What genetic studies will be done and what part will my DNA sample play?

(DNA samples will be collected only on those ages 20 or over.)

A Genetic studies look at the DNA found in cells. We will store part of the blood and saliva sample that we collect in the exam center for future genetic studies. We will keep this material for an unlimited time. Studies of human genes are helping us learn about many diseases and health conditions. The information from people who are part of NHANES could help that effort.

If you wish to have your samples used for future genetic studies, you will have a chance to say so when you sign this consent form.

$Q \quad$ How can I remove blood, urine, or saliva samples from the specimen bank?

$A$ In the future, if you want samples removed from the specimen bank, call us toll-free at 1-800 452-6115.

The results of continuing study of your stored specimens may help find new ways to prevent, treat, and cure many diseases.

For persons ages 7 and over, check this box

$\square$ I agree that my blood, urine, and saliva (if applicable) may be kept for future health studies

For parent/guardian of a child under the age of 18 , check this box

$\square$ I agree that my child's blood and urine may be kept for future health studies

Genetic testing studies may be done with DNA samples collected only on those ages $\mathbf{2 0}$ or over. If you wish to have your samples used for future genetic studies, check the box below:

Only for persons ages 20 and over, check this box

I agree that my blood and saliva may be kept for future studies using my genes to help understand genetic links to medical conditions.

Signature of participant age 7 or over

Signature of parent/guardian of participant under 18

Date

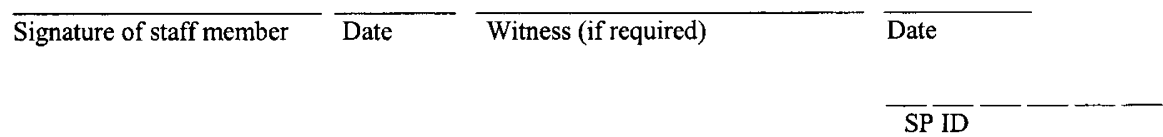

Public reporting burden of this collection of information is estimated to average 6.6 hours per response for total participation, including the time for reviewing instructions, searching existing data sources, gathering and maintaining the data needed, and com pleting and reviewing the collection of information. An agency may not conduct or sponsor, and a person is not req uired to respond to collection of information unless it displays a currently valid OMB control number. Send comments regarding this burden estimate or any other aspect of this collection of information, including suggestions for reducing this burden to CDC/ATSDR Reports Clearance Officer; 1600 Clifton Road, MS D-24, Atlanta, GA 30333, ATTN : PRA (0920-0237). 